DOI: $10.13037 /$ ci.vol21n45.6170

\title{
Comunicação e Identidade organizacional da Igreja Adventista do Sétimo Dia: estudo de Manual de Gestão de Crise e da relação de sentido em duas repercussões na mídia
}

\section{COMMUNICATION AND ORGANIZATIONAL IDENTITY OF THE SEVENTH-DAY ADVENTIST CHURCH: CRISIS MANAGEMENT HANDBOOK STUDY AND THE RELATIONSHIP OF MEANING IN TWO MEDIA REPERCUSSIONS}

\section{- Felipe Diemer de Lemos ${ }^{1}$}

ORCID - https://orcid.org/0000-0003-0270-6886

(Universidade Católica de Brasília, Programa de Pós-graduação em Comunicação, Faculdade de Comunicação da Universidade de Brasília. Brasília-DF, Brasil)

\section{Florence Marie Dravet ${ }^{2}$}

ORCID - https://orcid.org/0000-0002-3822-3627

(Universidade Católica de Brasília, Programa de Pós-graduação em Comunicação, Faculdade de Comunicação da Universidade de Brasília. Brasília-DF, Brasil)

\section{Luiz Carlos Iasbeck ${ }^{3}$}

ORCID - https://orcid.org/0000-0002-5870-1200

(Universidade Católica de Brasília, Programa de Pós-graduação em Comunicação, Faculdade de Comunicação da Universidade de Brasília. Brasília-DF, Brasil)

\section{Robson Dias ${ }^{4}$}

ORCID - hrcttps://orcid.org/0000-0003-1560-2058

(Universidade Católica de Brasília, Programa de Pós-graduação em Comunicação, Faculdade de Comunicação da Universidade de Brasília. Brasília-DF, Brasil) 


\section{Resumo}

$\mathrm{O}$ artigo exploratório analisa a tensão existente entre os conceitos de identidade organizacional (IASBECK, 1997) e comunicação em situações de crise e um dos resultantes desta relação, que é a possibilidade de ressignificação da própria identidade da organização. Isso é mostrado a partir da perspectiva da gestão de crise no contexto desenvolvido por uma organização religiosa, a saber, a Igreja Adventista do Sétimo Dia no Brasil, utilizando o conceito de irritações de Luhmann (2010). Para tanto, a análise empírica é feita em duas fontes de evidências: análise do Manual de Crise da instituição (1) e repercussão na mídia de duas crises no contexto da disputa de sentidos (2). Resultados desta análise empírica procuram evidenciar a relação direta entre o processo de gerenciamento da crise e a maneira como este processo pode conduzir a contribuições para a identidade da organização. A crise, por isso, conceitualmente vai além da ideia apenas de um problema, mas de uma oportunidade de ressignificação.

Palavras-chave: Comunicação organizacional. Crise; Identidade organizacional. Igreja adventista do sétimo dia.

\section{Abstract}

The exploratory article analyzes the tension between the concepts of organizational identity (IASBECK, 1997) and communication in crisis situations and one of the resultants of this relationship, which is the possibility of resignifying the identity of the organization itself. This is shown from the perspective of crisis management in the context developed by a religious organization, namely the Seventh-day Adventist Church in Brazil, using Luhmann's (2010) irritation concept. Therefore, the empirical analysis is made from two sources of evidence: analysis of the institution's Crisis Manual (1) and media repercussions of two crises in the context of the dispute of meanings (2). Results of this empirical analysis seek to highlight the direct relationship between the crisis management process and the way this process can lead to contributions to the organization's identity. The crisis, therefore, conceptually goes beyond just the idea of a problem, but of an opportunity for resignification.

Keywords: Organizational communication. Crisis. Organizational identity. Seventh-day Adventist Church.

\section{Introdução}

É importante compreender a relação que pode ser estabelecida entre a comunicação das organizações, ou simplesmente comunicação organizacional, e o processo de gestão de crise, bem como o de consolidação da identidade das próprias organizações. Um ponto de partida interessante para se entender que há uma correlação entre os conceitos vem de uma ilustração bem peculiar no mundo corporativo.

Imagine um executivo de uma grande corporação multinacional que, subitamente, vê-se envolvido em um escândalo relacionado a abuso sexual infantil. Análises superficiais e apressadas podem imaginar que a figura do executivo, apenas, é afetada pelo ocorrido. Especialmente quando toma dimensão no âmbito público. Mas o conhecimento da comunicação organizacional mostra algo mais profundo. E é possível ver em um episódio 
desta natureza uma crise percebida, também, em relação à organização na qual este executivo atua. Torna-se, portanto, necessária a ação específica de um gerenciamento desta crise. Atividade esta, como bem observa o estudioso Wilson Bueno, em que

A comunicação efetivamente estratégica pressupõe um trabalho de planejamento para gerenciar momentos difíceis, como toda crise costuma ser. Há vários processos, ações e estratégias que devem ser definidos, elaborados e implementados visando prevenir, gerenciar ou mesmo evitar as crises (BUENO, 2009, p. 144).

Esta estratégia comunicacional é o que predominantemente caracteriza a comunicação das organizações. E a estratégia, neste caso, tem a finalidade de arregimentar da melhor forma as decisões comunicacionais com a finalidade de tornar a crise mais amena para a organização. E mais do que isso. É possível ver uma interferência referente à própria identidade desta organização, à forma como a organização se apresenta e fundamentalmente é.

O conceito de identidade organizacional está conectado a vários aspectos. Podemos pensar, por isso, em identidade organizacional caracterizada de duas maneiras principais, contudo conectadas entre si, para as finalidades propostas nesse estudo. Uma primeira maneira de pensar a identidade organizacional tem relação com a função dos aspectos culturais típicos da subjetividade dos indivíduos que fazem parte da organização e que são, em essência, bastante influentes para a conformarem.

Por outro lado, podemos analisar a identidade organizacional segundo o aspecto relacional que nos interessa muito aqui, com uma outra base: a ideia de que a identidade se constitui a partir de reconhecimento ou convenção. Segundo Abbagnano (1986), é possível encontrar na história da filosofia três fundamentos básicos para se entender o conceito de identidade: a identidade como signo de si mesma (entendida como unidade de substância); a identidade em relação a outro existente (como competência substitutiva) e a identidade como padrão de reconhecimento (como convenção). Iasbeck (1997) interpreta essa tripla conceituação de identidade dentro das categorias peirceanas em que

Quando traduz a si mesma, a identidade é captada pelo signo como qualidade, sensação de integridade; quando surge da confrontação entre diferenças físicas ou brutas entre objetos, fenômenos ou ideias, o que corresponde a uma espécie de insistência da existência de outro elemento que não apenas o ser idêntico a si mesmo, é percebida pelas afinidades que destaca, num espectro de 
diferenças; quando arbitrada pelo hábito (repetições), pelo uso e pelos códigos culturais, surge como critério, como símbolo, como paradigma (IASBECK, 1997, p. 123).

Podemos trabalhar, por isso, com a ideia de identidade organizacional nesse terceiro aspecto, ou seja, "quando arbitrada pelo hábito, pelo uso de códigos culturais, surge como critério, como símbolo, como paradigma”. E essa identidade formada se dá na relação entre o discurso organizacional (o que a organização diz ser) por meio de crenças e princípios e a interação com os elementos típicos da percepção de imagem dos públicos com os quais a organização lida, sejam os mais internos quanto os externos.

O primeiro aspecto cultural, ligado à identidade organizacional, é bastante importante em nossa discussão, uma vez que a identidade, na avaliação de vários autores, é construída por meio das subjetividades, da vida de cada uma das pessoas, e isso envolve, obviamente, as diferentes culturas as quais estamos todos submetidos de uma forma ou outra. Seja a cultura proveniente de nossa origem étnica ou a cultura organizacional específica que nos influencia em um determinado período da existência. A construção da identidade se dá, também, no aspecto organizacional, uma vez que, como sabemos, as organizações são sistemas vivos que interagem uns com os outros, dinâmicos, não inflexíveis e imutáveis.

É preciso observar que o ambiente histórico e social em que as organizações se situam é determinante para a própria identificação dessa organização. Não se admite, conceitualmente, organizações estabelecidas fora de contexto, porque seu discurso, assimilado pelas pessoas que a compõem, tampouco existem em um vácuo cultural (FREITAS, 1999, p. 53). Castells vai além e infere que essa construção da identidade, falando de forma geral, vale-se de diferentes elementos culturais para existir.

Não é difícil concordar com o fato de que, ao ponto de vista sociológico, toda e qualquer identidade é construída. A principal questão, na verdade, diz respeito a como, a partir do que, por quem, e para que isso acontece. A construção de identidades vale-se da matéria-prima fornecida pela história, geografia, biologia, instituições produtivas e reprodutivas, pela memória coletiva e por fantasias pessoais, pelos aparatos de poder e revelações de cunho religioso (CASTELLS, 1999, p. 23).

Alguns autores procuram classificar a identidade organizacional como decorrente da interferência das identidades individuais dentro das organizações. Tem muito a ver 
com as subjetividades e com a forma, por isso, como esses indivíduos enxergam a organização. Asforth e Mael (1996) falam do julgamento e percepções desses indivíduos e quão preponderantes esses elementos são para formar a identidade de determinada organização. Em breve comentário da obra dos autores, Machado (2006) desenvolve que

Para Asforth e Mael (1996), a identidade organizacional é o julgamento dos indivíduos sobre os aspetos distintos, centrais e duradouros da organização. Os aspectos centrais, segundo os autores, estão ligados aos sistemas de crenças, valores e normas da empresa; os aspectos distintos estão relacionados à exclusividade da organização, referência para garantir a identificação organizacional e definir as fronteiras da organização. $O$ último elemento, o duradouro, é o que garante a continuidade da empresa e sua constante transformação. Para os autores, a identidade é socialmente construída no âmbito organizacional, em torno das percepções dos indivíduos sobre a essência ou a 'alma” da organização (MACHADO, 2006, p.3).

Isso mostra o quão importante é o fato de os públicos, com sua óbvia influência de distintas culturas, que interagem com a organização e colaboram no processo de formação da própria identidade organizacional. A cultura organizacional, que está fundamentada nas práticas diárias ou cotidianas de quem vive a realidade nas organizações, é um fator de formulação e de estruturação da identidade organizacional na medida em que que vem como um somatório de quem são e como pensam as pessoas ou públicos de contato com essa organização (ALMEIDA, 2005, p. 28).

O que se sobressai nesse conceito de cultura e identidade organizacional nada mais é do que a identificação de que os indivíduos obviamente constroem essa identidade, na medida em que desempenham papéis a partir das suas próprias visões de mundo e compartilham sentidos. E que esse fenômeno, por isso, pode muito bem ser reputado como eminentemente relacional, uma vez que a subjetividade dos indivíduos é construída na organização e o contrário também se aplica. Estabelecem-se as ideias de pertencimento, de grupo e de filiação, bastante caros para alguns autores.

Para autores como Chanlat (1992), a identidade coletiva emerge a partir das relações entre os indivíduos, quando da formação dos grupos sociais. Nesses grupos, cada indivíduo seria responsável por representar um determinado papel, uma função social dentro do grupo, o que implicaria na noção de pertencimento coletivo, num sentimento de filiação. Já para Hatch e Schultz (2002), a identidade organizacional é coletiva no sentido de ser uma 
representação compartilhada. Segundo essas mesmas autoras, o conceito de identidade organizacional tem suas raízes nos estudos relacionados à formação de identidade presentes na filosofia, psicologia, sociologia e antropologia (CARRIERI; PAULA; DAVEL, 2008, p. 130).

\section{Comunicação, identidade e irritações}

Já chegamos a uma definição do que, aqui nesse trabalho, interessa-nos como um conceito para identidade organizacional. Ao mesmo tempo, entendemos que é importante fazer a necessária conexão com a ideia de comunicação nas organizações. A comunicação nas organizações, ou comunicação organizacional, é considerada vital para a própria existência das organizações, uma vez que os objetivos organizacionais só podem ser alcançados ou atingidos em um contexto de comunicação e interação das pessoas que estão dentro da organização e se relacionam de alguma forma com ela.

A relação, seja no campo da comunicação em geral ou mais especificamente no âmbito daquilo que ocorre no plano organizacional, pressupõe junções ou integrações em que as partes, apesar de terem comportamentos diferentes, acabam criando uma fusão produto do relacionamento em que fatores individuais ficam em segundo plano.

A mesma linha de pensamento que enxerga a comunicação e a relação pode ser transposta do plano individual para sistemas e organizações. É o que diz a teoria de Niklas Luhman (2006), ao conceituar comunicação como resultado de três seleções: a sinalização de alguma coisa, a percepção do outro estabelecendo a intenção de comunicar e, por fim, o entendimento de que houve comunicação. Marcondes Filho (2004, p. 458), ao comentar Luhman, explica que seria a síntese de sinalizar, informar e entender. E esse processo comunicacional é permanente, caracterizando os sistemas sociais.

Confirmamos com base no que já foi falado anteriormente que a comunicação organizacional, a exemplo da identidade da organização, sofre semelhante influência em sua formação. Ou seja, deixa-se de pensar a comunicação de uma determinada organização como meramente o movimento de se expressar o discurso organizacional para ser assimilado pelos públicos de interesse. Mas, por outro lado, leva-se em conta, para a construção da identidade e, obviamente, da própria comunicação organizacional, como reagem esses públicos a essa mensagem. É o próprio processo contínuo de interação, de relacionamento. 
As organizações em geral, como fontes emissoras de informações para seus mais diversos públicos, não devem ter a ilusão de que todos os seus atos comunicativos causam os efeitos positivos desejados ou que são automaticamente respondidos e aceitos da forma como foram intencionados. É preciso levar em conta os aspectos relacionais, os contextos, os condicionamentos internos e externos, bem como a complexidade que permeia todo o processo comunicativo. Daí a necessidade de ultrapassarmos a visão meramente mecanicista da comunicação para uma visão mais interpretativa e crítica (KUNSCH, 2003, p. 3).

Por conta dessa clara proximidade entre comunicação e identidade, no que diz respeito à própria formação desses conceitos dentro da organização, é possível falar que ambos, também, constroem-se mutuamente. A comunicação organizacional tem a propriedade de ser um canal de expressão da identidade organizacional, ao transmitir o conteúdo do discurso (missão, valores, princípios, crenças, etc), colaborando para que os públicos formem percepções sobre esse discurso e, ao mesmo tempo, que o discurso esteja suscetível a essas interferências.

É através da comunicação institucional que se forma e se constrói a imagem e a identidade da organização. Ela fortalece o seu lado administrativo, consegue a credibilidade necessária, estabelece um conceito para a empresa. Vinculada aos aspectos corporativos / institucionais da organização, traz atividades que difundem informações de interesse público sobre filosofias, políticas e práticas da mesma. Assim colaborando para a construção de uma imagem (aquilo que o público vê e pensa a respeito da instituição) e da identidade corporativa (o que a empresa é de fato), ela enfatiza os aspectos relacionados com a missão, a visão e os valores da organização e contribui para o desenvolvimento institucional. Por isto tem importância significativa (DILLY, 2011, p. 8-9).

Em qualquer tipo de processo relacional, no entanto, há ruídos ou fenômenos caracterizados por algum tipo de quebra ou ruptura. É interessante constatar que, na ideia de acoplamento estrutural dos sistemas com o ambiente, dentro da perspectiva luhmniana de comunicação, surge, também, um fator denominado irritação ou perturbação, conforme colocado pelo sociólogo (LUHMAN, 2010). Trata-se de um processo interno do sistema em que ele mesmo percebe essas irritações como elementos que, de certa maneira, quebram a estabilidade de desenvolvimento do sistema e causam uma interferência. Um sistema pode ser, no caso, uma organização, seja uma empresa, uma instituição, etc. 
Em muitos casos, o acoplamento estrutural é responsável por perturbações e irritações para o sistema porque, além de estruturas de outros sistemas funcionarem como elemento de apoio às operações do sistema, elas aparecem também como informações desorganizadas e presentes em seu ambiente. Assim, o acoplamento estrutural é um dos elos de ligação do sistema ao seu ambiente (NEVES, 2005, p. 55).

Essas perturbações ou irritações, é importante salientar, ocorrem a partir do entendimento de um confronto interno do sistema com os acontecimentos externos. $\mathrm{O}$ benefício desses acontecimentos externos para o sistema (organização) se dá somente quando ocorre a dotação ou aplicação de sentido a essa irritação a fim de que seja útil de alguma forma. Para Luhmann (2010), a irritação ou perturbação só terá força sobre um sistema social quando passar pelo filtro da seletividade que ocorre no que ele denomina de sistema psíquico (a nossa mente), ou, em última instância, aquilo que percebemos ou a que atribuímos sentido.

O desenvolvimento do próprio sistema ocorre por meio de sucessivo processo comunicacional com as irritações. Por exemplo, uma organização educacional (que poderíamos classificar de um sistema social) é confrontada com um determinado sistema jurídico (outro sistema social) que causará inevitavelmente irritações nessa relação entre os dois a partir de alguma percepção provocada até por um acontecimento externo (que seria parte da irritação). É o caso, por exemplo, de uma lei que entra em choque ou cria algum tipo de problema para determinado regulamento de uma escola. As irritações são elementos constantes de desajuste e até desequilíbrio nos sistemas, e que afetam seu desenvolvimento. Mas são elementos que acabam sendo incorporados e não são estranhos. Sem eles, o sistema nem se enxergaria como sistema.

Dentre o conjunto de acoplamentos estruturais nos quais o sistema participa, existem alguns que são mais significativos para o seu funcionamento, que produzem mais irritação, com uma frequência maior e que são mais selecionados para serem utilizados como informação no processo comunicativo interno. Estes acoplamentos são responsáveis por um fluxo estrutural e por uma parcela de evolução do sistema. Sob esse aspecto, estes acoplamentos podem se desenvolver como sistemas autônomos, sobretudo como sistemas de organização (NEVES, 2005, p. 59). 
Essas irritações, na relação entre os diferentes sistemas, estão ligadas a acontecimentos externos também. E, nesse contexto, podemos considerar a existência das crises organizacionais. Voltando ao exemplo anterior, é plenamente possível que, em dado momento, um aspecto da legislação educacional (elemento presente no sistema jurídico) entre em rota de colisão direta ou indireta com as normas do colégio (elemento presente na escola enquanto sistema organizacional) e se forme uma crise organizacional. As crises, assim, poderiam ser, por essa ótica, também, identificadas como acontecimentos externos que são percebidos, em última medida, como uma parte das irritações dos sistemas.

Comumente, as crises organizacionais estão associadas a apenas acontecimentos com efeitos negativos para uma organização. Definições comuns apresentam as crises como eventos inesperados, surpreendentes e que estabelecem um ambiente de incerteza e insegurança nas organizações junto a seus públicos e geram, por isso, demanda por respostas imediatas (SILVA NETO, 2010). Seriam, nesse caso, como ameaças às expectativas da própria organização quanto a seus resultados, performance e, consequentemente, identidade. Nesse caso, um evento não previsto, também com repercussão inesperada (COOMBS, 2007).

Certamente essa faceta é real quando se fala em crises. São os eventos que acometem empresas, igrejas, instituições filantrópicas em geral, obrigando essas organizações a reagirem de alguma forma a isso, pois são evidentemente afetadas. Ao mesmo tempo, é importante se pensar no entendimento das crises organizacionais, também, por um outro ângulo. Já que essas crises estão relacionadas com a percepção, isso implica que determinados acontecimentos são percebidos ou enxergados pela organização e isso ultrapassa o fato em si. Há, também, uma relação com o próprio discurso organizacional. Até aqui, constatamos que essa relação entre a imagem percebida e o discurso organizacional está bastante clara na identidade organizacional.

\section{Comunicação em situações de crise}

Já exploramos bastante a natureza, origem e conceituação de crises organizacionais no início deste projeto, mas aqui retomamos a ideia com ênfase na comunicação organizacional que tem interferência, portanto, no processo, tanto de gerenciamento da crise como do gerenciamento da identidade, uma vez que as ideias estão intrinsecamente relacionadas. 
A atividade de gerenciamento da crise é caracterizada como eminentemente comunicacional/reputacional, ou seja, seu impacto é mais expressivo sobre a imagem e discurso organizacionais e, por conseguinte, a influência ou repercussão que ocasionam no caso da identidade e da comunicação da organização. No entanto, esse gerenciamento de modo geral não é uma prerrogativa apenas do profissional de comunicação, mas normalmente sob a coordenação de um comitê multiprofissional que possa auxiliar na condução de todos os aspectos que dizem respeito a esse gerenciamento (FORNI, 2007, p. 200).

Alguns estudiosos do tema afirmam, também, haver uma diferenciação entre a gestão de crises sob o ponto de vista administrativo e a gestão comunicacional das crises, mais focada na dimensão eminentemente de viés relacionado às ações tipicamente consideradas ligadas à comunicação. Por outro lado, há nítido empenho de alguns autores, como Prestes (2007), no sentido de fortalecer a ideia de a comunicação ter não apenas um papel acessório na gestão de crise, mas preponderante. Prestes trabalha com a ideia de que a comunicação de risco é fundamental para um bom relacionamento entre a organização e seus públicos, em relação a riscos e, em última instância, em situações de crise. Para Torquato (2002, p. 60), "a comunicação é vital para a administração das crises vividas pela organização".

Em torno disso, formulou-se a ideia de gestão de crise, compreendendo-se que a crise é inerente às organizações, que ultrapassa a ideia de risco e emergência, mas que, de certa maneira, nem sempre é evitável. Por nem sempre ser impossível impedir que exista (e talvez na maioria das situações isso ocorra), admite-se a necessidade de um trabalho de gestão ou gerenciamento de crise. Há uma corrente que admite as crises como eventos violentos e dolorosos. Não haveria crise sem sofrimento. Embora não seja uma característica implícita nas crises, há uma relação muito próxima entre crises mal administradas e esses eventos dolorosos, porque o preço da má gestão de crise pode ser muito elevado. Se a organização, apesar da crise, consegue conduzir o fato negativo, seguindo os preceitos básicos de gestão de crises, ameniza sua letalidade. Pode até ser, ao contrário, uma oportunidade de crescimento, afirmação e aprendizagem (FORNI, 2013, p. 11).

A específica comunicação em situações de crise é, portanto, uma questão muito estratégica porque tem implicações quanto à interferência em elementos ligados ao risco que corre a identidade da organização em um episódio assim. Uma das principais funções da comunicação durante uma crise vivida pela organização tem relação direta com a 
identidade e consiste na demonstração de que a organização evoca sua legitimidade ao responder a um determinado problema e informar de que maneira vai lidar com a situação adversa. É um esforço para resgatar ou, ao menos, não permitir um abalo significativo na credibilidade e na coerência entre o discurso (a forma de ser da própria organização) e a sua imagem percebida pelos públicos que são direta ou indiretamente afetados pela crise em curso.

A comunicação competente contribui também para tornar claro para as comunidades envolvidas em desastres (bem como para a mídia e outros interessados) quais são as fontes que podem, com credibilidade, prestar informações sobre o ocorrido, evitando que as chamadas fontes oportunistas, comuns nesses momentos, possam valer-se da situação para disseminar a desinformação ou mesmo o pânico. Esse esforço legitima as autoridades (que, evidentemente, devem ter credibilidade junto às comunidades) responsáveis pela gestão das situações críticas, criando uma relação de confiança, indispensável para o encaminhamento de soluções e para o comprometimento dos cidadãos (BUENO, 2012, p. 10).

Outro aspecto importante no que diz respeito à comunicação em situação de crise, na relação com a identidade da organização, é quanto ao fator de persuasão e convencimento. Forni (2007), citando alguns autores, menciona três atitudes principais que podem ser adotadas, sob o ponto de vista comunicacional da organização, diante da necessidade de uma comunicação ativa durante uma crise organizacional: negação da existência da crise, diminuição da importância do efeito negativo da situação ou trabalho para alterar a maneira como a organização é vista naquele momento pelos públicos com os quais possui contato (FORNI, 2007, p. 211).

A última citação atribuída a Forni está diretamente relacionada a uma tentativa de a organização, no decurso de uma crise pela qual está passando, ressignificar o episódio adverso segundo as percepções existentes. Kent (2010) também trata da mesma questão ao explicitar que as crises organizacionais vão além do que pontualmente se percebe quanto a prejuízos econômicos ou de reputação momentâneos. Mas são essencialmente problemas éticos ou sistêmicos, o que pressupõe uma abrangência muito maior e que ultrapassa uma mera atividade de "abafar" a crise específica.

Crises organizacionais são frequentemente consideradas problemas econômicos ou de reputação ao invés de problemas éticos ou sistêmicos. "A 
boa organização se comportando bem", como Quintiliano poderia ter afirmado, é o que os profissionais de relações públicas devem estar trabalhando para, ao invés de como restaurar uma reputação manchada, ou trabalhando para fazer as pessoas esquecerem o que uma organização fez, em vez de se apegarem à crise e consertando o problema (KENT, 2010, p. 710).

Ampliando um pouco mais essa ideia de ressignificação, é fundamental olhar para uma perspectiva em que a gestão ou gerenciamento da crise é vista não apenas como um momento de esforços conjuntos para preservar a identidade, enquanto se tenta lutar contra um problema causado ou não diretamente pela organização, contudo uma reflexão em direção à possibilidade de uma mudança mais profunda da própria organização quanto a sua forma de ser e atuar. Há um interesse, especialmente naqueles que fundamentam seus argumentos na chamada Teoria Situacional de Comunicação da Crise (COOMBS; HOLLADAY, 2002), de compreender a crise organizacional como uma oportunidade de aprendizagem da organização com possíveis erros cometidos, a fim de melhorar, tanto seus processos de gerenciamento de futuras crises quanto exercer um maior cuidado com a própria reputação.

Reputação e identidade organizacional são conceitos bastante interligados também, como já vimos, corroborando com as conclusões de Jorge (2010), pesquisador que buscou entender se a reputação de organizações financeiras, sobretudo as localizadas em Portugal, servia como uma proteção diante do caos estabelecido com a crise financeira que assolou o mundo em 2008. O ponto de partida dessa crise foi o subprime americano, uma situação desencadeada em 2006, mas que avançou por mais tempo com impactos na economia global, a partir da ruptura de instituições de crédito dos Estados Unidos, que concediam empréstimos hipotecários de alto risco.

Nas considerações finais de seu trabalho, o pesquisador argumentou que

A reputação tem um efeito protetor sobre a performance organizacional, tanto financeira, como reputacional, e que este pode ser verificado empiricamente. Esta sugestão vai ao encontro do pressuposto de que a reputação é um ativo, que deve ser gerido de forma a acrescentar valor e a ser uma vantagem competitiva, no contexto empresarial (JORGE, 2010, p. 113).

O que chama bastante a atenção na conclusão do pesquisador português é o fato de a reputação poder ou dever ser gerida e que a mesma pode ter um efeito protetivo direto sobre a performance organizacional especialmente frente a uma crise que afeta a 
organização. Ou seja, a reputação protege não apenas a imagem ou fortalece o discurso, mas a performance da organização, nas palavras de Jorge, algo muito similar ao que compreendemos como a identidade organizacional.

Ulmer, Sellnow e Seeger (2010) entendem que a comunicação das organizações, diante de crises, precisa levar em conta a aprendizagem organizacional. Trazem a ideia de comunicação caracterizada pela ética que olhe para o futuro da organização e não se limita ao problema pontual existente que preocupa por algum tempo.

As organizações também devem considerar comunicação ética ao invés de interpretar as evidências em torno de uma crise com a intenção de enganar ou confundir o público. Sugerimos que as organizações considerem enfatizar uma visão mais prospectiva para o futuro em sua comunicação de crise em vez de focar retrospectivamente na responsabilidade pelo evento (ULMER; SELLNOW; SEEGER, 2010, p. 692).

No contexto da Igreja Adventista do Sétimo Dia, as crises organizacionais são encaradas dentro do contexto da comunicação, em que diretrizes são aplicadas para se gerir isso. A organização enxerga a gestão de crises como um trabalho relacionado diretamente à comunicação organizacional. Como já vimos, as crises, no processo comunicacional de uma organização, acabam, de certa forma, fazendo parte do próprio ser da organização e possuem uma íntima relação com a percepção. Ou melhor ainda, da construção da imagem corporativa, na interação com o discurso organizacional. E isso deriva, ainda, para uma preocupação com questões identitárias. Essa preocupação com crises passa a ser, por conseguinte, uma realidade, também, de uma organização religiosa como a Igreja Adventista do Sétimo Dia no Brasil, enquanto atuante com diferentes públicos, com toda a sua política comunicacional fortemente atrelada a sua missão enquanto instituição.

Dessa forma, é possível identificar, nos documentos da organização, uma preocupação com a gestão profissional de crises. Isso está caracterizado nos documentos e materiais oficiais que conduzem o direcionamento adventista no que tange à estratégia nessa área. Na visão comunicacional adventista, a gestão de crises procura abarcar a compreensão de uma atividade eminentemente comunicacional com nuances nas atuações de caráter jurídico e/ou administrativo.

Nos objetivos gerais do Departamento de Comunicação da Igreja Adventista na América do Sul, consta que um dos objetivos desse departamento é o de "auxiliar os líderes na prevenção e gestão de crises”. 
Além disso, um outro ponto que também interessa aqui, nesta pesquisa, é a menção, nas atribuições do profissional denominado assessor de comunicação ou gerente de comunicação, que o mesmo é responsável, entre outras atividades, por "participar ativamente do comitê de prevenção e gestão de crises".

Em 2012, a organização adventista produziu um manual de práticas de gestão de crises de imagem, voltado, inclusive para pastores e diretores de comunicação nas congregações locais. Em 2017, o material sofreu uma atualização e passou a se chamar Manual de gestão de crises com repercussão na opinião pública. Na sua introdução, o material explica o seu objetivo ao afirmar que:

A ideia é que esse material sirva como um suporte de orientações a respeito de como a organização adventista deve proceder antes, durante e depois de algum tipo de crise que possa abalar sua imagem perante a opinião pública. Opinião pública não se limita aos meios de comunicação convencionais como TV, rádio, jornal, revista, portais, etc. São todas as pessoas que, de alguma forma, enxergam o que os adventistas fazem e se relacionam com a organização. Os públicos de interesse da organização.

\section{Manual de gestão de crise da Igreja Adventista}

O Manual de Gestão de Crises com Repercussão na Opinião Pública da Igreja Adventista do Sétimo Dia teve sua primeira versão produzida em 2010 e sofreu atualização em 2017. O material, um produto do Departamento de Comunicação da Igreja, faz uma conexão entre a gestão profissional de crises, com suas nuances, processos e características em geral e a própria gestão da imagem no aspecto da comunicação organizacional e apresenta a ideia de estabelecimento de comitês de gestão de crise em sedes regionais, além de outros procedimentos pragmáticos que possam ser úteis para ações administrativas com caráter mais preventivo e diante de situações de crise.

$\mathrm{Na}$ sua introdução, o Manual afirma que

O presente manual não esgota o assunto, mas tem por objetivo propor alternativas práticas a fim de que a sobriedade, a prudência, o dever de vigilância, manifestem-se nas práticas da Igreja Adventista do Sétimo Dia, especialmente quando diante de situações críticas, de crises (MANUAL DE GESTÃO DE CRISES COM REPERCUSSÃO NA OPINIÃO PÚBLICA, 2017, p. 2). 
Em termos de estrutura, o Manual compõe-se basicamente de um capítulo inicial que identifica situações de risco e de crise e outro capítulo que diferencia risco de crise e trata de aspectos gerais importantes na prevenção. No terceiro capítulo, o Manual se propõe a exemplificar a gestão da crise a partir da ótica de estágios com a crise em estado latente (o risco e a ameaça), a crise em andamento com todas as suas características próprias como, por exemplo, o estabelecimento de percepções diferenciadas por parte dos públicos que a veem, e o momento pós-crise quando a fase aguda arrefece e são indicadas avaliações administrativas. O quarto capítulo aborda especificamente o papel do Comitê Gestor de Crise dentro da organização adventista, bem como sua função e relevância. $\mathrm{O}$ quinto capítulo apresenta procedimentos sugeridos para se lidar com a crise no local onde ela ocorre em termos pragmáticos. E, finalmente, o sexto capítulo, expressa a visão da organização adventista sobre a comunicação de crise com itens específicos para interface com meios de comunicação, públicos internos e externos e apoio na orientação dos portavozes.

Uma análise crítica desse Manual chama a atenção para alguns aspectos interessantes relacionados à maneira como a própria organização adventista enxerga as crises e a maneira de gerenciá-las. Um primeiro aspecto se refere à identificação sobre crise e risco a fim de que, para o gestor, fique mais evidente do que tratam esses conceitos. O Manual não se preocupa com algum tipo de aprofundamento para estabelecer uma variedade de reflexões acerca do que é crise e nem risco, pelo menos sob o ponto de vista conceitual, provavelmente por se tratar de um material cujo conteúdo apresenta um viés mais pragmático voltado a profissionais da área administrativa, comunicacional e jurídica que precisam lidar com o assunto de forma cotidiana. Isso inclui, também, uma espécie de fluxograma que orienta a forma mais viável de gerenciar uma crise operacionalmente no cotidiano da organização (ver infográfico 1). 


\section{Gráfico 1 - Infográfico 1}

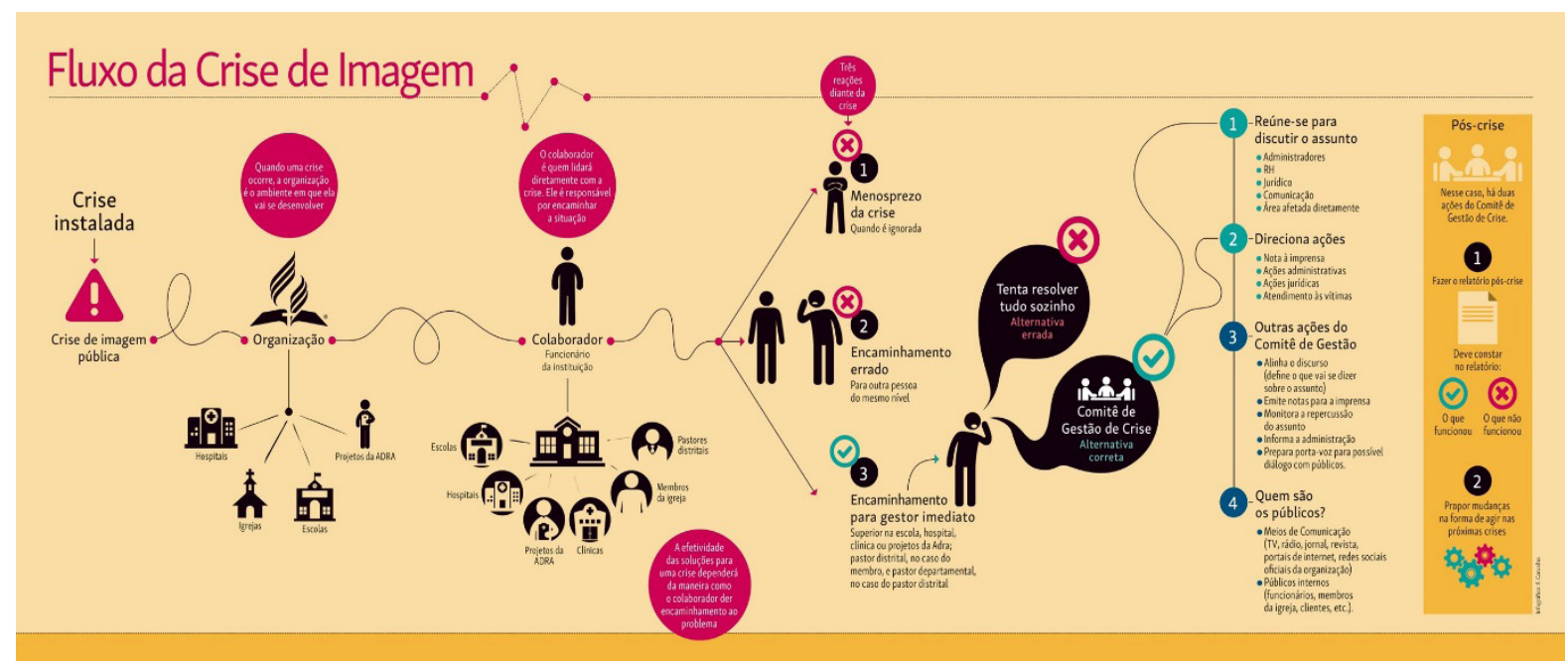

Fonte: Manual de Gestão de Crises com Repercussão na Opinião Pública (Assessoria de Comunicação da

Divisão Sul-Americana da Igreja Adventista do Sétimo Dia, 2017).

O Manual está mais focado em oferecer orientações sobre procedimentos preventivos e mesmo de ação no decorrer de uma situação de crise que possa ter implicações no que tange à exposição pública da organização, porém, por outro lado, deixa de tratar da identidade organizacional enquanto aspecto que recebe influência nessa relação entre discurso-crise organizacional-imagem percebida. Em realidade, por seu caráter mais pragmático, o Manual evita a apresentação de conceitos como imagem ou mesmo identidade. Limita-se, nas primeiras páginas, a trazer rápidas definições sobre risco e crise.

Ainda que não prime por uma discussão mais teórica, em virtude de ser um produto essencialmente direcionado a gestores operacionais e tomadores de decisão em nível administrativo superior da própria organização, o Manual atende a questões de fundo concernentes à imagem e ao discurso. Um ponto forte, por exemplo, é a elaboração de um padrão estratégico para a comunicação quando a crise está em curso e uma orientação relacionada à própria expressão do discurso da organização. Quando fala das atribuições do porta-voz, é sugerido no Manual que essa pessoa "não deve ser escolhida porque fala bem ou porque é chefe, mas porque possui equilíbrio emocional, capacidade de reagir bem a perguntas difíceis e ter disponibilidade para se comunicar com os públicos" (DIVISÃO SUL-AMERICANA DA IGREJA ADVENTISTA DO SÉTIMO DIA, 2017, p. 8). Aí está explícita uma forma de o porta-voz, aquele que em situações de crise tem a responsabilidade de se comunicar com os públicos acerca do posicionamento 
da organização, apresentar o discurso organizacional e, portanto, colaborar para que a mensagem da organização seja previamente pensada e tornada pública em consonância com os princípios que norteiam a própria organização. Foi institucionalizado, por meio desse Manual, o alinhamento do discurso diante de uma crise a fim de conseguir enfrentar uma situação em que, notadamente, as percepções de imagem da organização costumam já sofrer danos e prejuízos.

Outro aspecto a ressaltar, também sobre o Manual, é a forte ênfase na estruturação de comitês de gestão de crise como instâncias em que estrategicamente se definem os protocolos de atuação. Dessa forma, esse item do Manual leva a se pensar detidamente sobre a maneira como a organização vai reagir, em diferentes frentes - inclusive pelo caráter multiprofissional do comitê - para antecipar possíveis situações de percepção negativa de sua imagem. Sobre o comitê, por exemplo, é dito que, entre as suas prerrogativas, está a de “ser responsável pelo monitoramento de informações que possam servir à instituição em casos de crise". Essa declaração a respeito do monitoramento ser estrategicamente ligado às tarefas do comitê diz muito sobre uma preocupação com o que pensam os públicos e efetivamente como eles veem o que está sendo divulgado.

\section{Comunicação de crises na organização adventista}

Para exemplificar um pouco do que se falou até agora sobre essa relação entre crises, imagem e discurso, pode ser importante observar dois casos, ligados à organização adventista. Foram escolhidos por se tratar de situações que apresentaram algumas características relevantes para o tipo de discussão que empreenderemos nesse projeto. Um dos fatores que pesou em favor da escolha dessas situações foi o de que se trata de episódios com forte repercussão diante da opinião pública (públicos internos e externos à organização) e que, portanto, exerceram um impacto quanto à imagem da organização. Uma evidência disso é o fato de que, dez anos depois do ocorrido, alguns veículos de comunicação ainda tratam do assunto e fazem questão de classificá-lo como de repercussão nacional.

É o caso de reportagem veiculada pelo portal G1, e datada do dia 29 de abril de 2017, em que, em determinado trecho afirma que 
Dez anos após uma menina de 1 ano e meio ter sido achada morta em uma pia batismal de uma igreja em Joinville, a defesa do homem que chegou a ficar mais de três anos preso pelo crime pede ao estado uma indenização de R\$ 8 milhões. $\mathrm{O}$ recurso não tem data para ser julgado. $\mathrm{O}$ processo foi anulado por falhas na investigação, e as circunstâncias da morte de Gabrielli Cristina Eicholz nunca foram esclarecidas (RBS TV, 2019).

Em entrevista com o jornalista, consultor de gestão de crises e ex-diretor de Comunicação da Igreja Adventista do Sétimo Dia na América do Sul, Siloé de Almeida, dimensionou o impacto da crise da morte da menina em Joinville para a organização. $\mathrm{O}$ profissional, que trabalhava em uma sede administrativa regional à época, foi acionado pela sede catarinense para dar um apoio no caso específico. Almeida afirmou que

O impacto foi grande devido à natureza (morte de uma criança) e pelo fato de ter ocorrido em um tanque batismal de uma igreja, de um templo em construção. O segundo motivo do impacto é que, na boa intenção, o presidente da Igreja na região, tentando atender bem a imprensa e familiares, tentando fazer o melhor, acabou se expondo, dando o próprio telefone, ouvindo a assessoria, eu diria que foi uma pessoa não treinada antes. Quem se colocou para fazer a gestão da crise não tinha treinamento, nem conhecimento do que fazer diante de uma adversidade tão grande.

O episódio do menino morto em uma sala de aula no mês de outubro de 2010 teve impactos internamente para a organização e, também, sob o ponto de vista externo. Conforme afirmou Ivan Góes (2017), então diretor associado da Rede de Educação Adventista na América do Sul, e que já dirigiu escolas e escritórios regionais da rede em vários estados brasileiros, é inegável o impacto externo e que, de acordo com seu entendimento, pode ser considerado sob ponto de vista positivo e negativo. Ele considerou, em entrevista concedida ao pesquisador, que "houve um impacto negativo, de maior ou menor repercussão do caso, pois algumas pessoas tentaram tirar proveito dessa situação para criticar a organização" (2017). Ele comentou que, em um caso pontual como esse, a percepção negativa para a imagem da organização é medida, em grande parte, pelo tipo de assessoria ou gestão que se faz da crise. "Quando há uma assessoria ou um treinamento, do tipo quem vai falar com a comunidade sobre o fato acontecido, o fato ainda pode ser ampliado ou diminuído", ressaltou (2017). 
Ao mesmo tempo, Góes (2017) pontuou que muitas pessoas, por conhecerem a Rede de Educação Adventista e seus valores, reagiram a esse episódio saindo em defesa da Rede e do que ela representa para elas. É importante ressaltar que os valores a que Ivan Góes se referiu na entrevista concedida estão presentes no próprio site oficial da Educação Adventista e, na sua essência, são opostos a um caso de morte por disparo em sala de aula. Na sua declaração de missão, delineada nesse site, está expresso que a missão é a de "promover, por meio da educação cristã, o desenvolvimento integral do educando, formando cidadãos autônomos, comprometidos com o bem-estar da comunidade, da pátria e com Deus" (2020).

Há um terceiro fator a ser mencionado que é o fato de que os dois episódios ocorreram com crianças, o que empiricamente pode ser considerado um elemento capaz de potencializar múltiplas percepções, especialmente em públicos muito importantes para a organização adventista, ou seja, os pais de crianças pequenas.

Nas falas desses gestores, é possível ver claramente noções já mencionadas sobre percepção de imagem (a forma como os públicos reagiram ao conteúdo divulgado nos meios de comunicação sobre uma das crises organizacionais) e, também, em relação ao discurso organizacional, uma vez que um dos entrevistados (Ivan Goés) mencionou a questão dos valores da organização como importantes no processo da própria gestão da crise organizacional.

\section{Considerações finais}

É fundamental se entender que as crises organizacionais fazem parte de organizações vivas, dinâmicas, com uma expressividade de identidade igualmente dinâmica e que, por isso, não são elementos estranhos e impensáveis. As crises inevitavelmente farão parte do desenvolvimento da própria organização na medida em que, como já falamos, permitem o aperfeiçoamento de discursos, de formas de lidar com os públicos para adequação às percepções, portanto não são elementos estranhos e alheios à realidade corporativa.

A partir da análise do Manual de Gestão de Crise e das entrevistas realizadas com as pessoas relacionadas com as crises, há possibilidade de se perceber que o processo de ressignificação da identidade organizacional é algo que, de alguma forma, começou a ocorrer no contexto do gerenciamento.

Certamente, para a identidade organizacional da Igreja Adventista, a morte de uma criança nas circunstâncias como as que caracterizaram o fato ocorrido na cidade 
de Joinville, em 2007, ou mesmo o disparo que levou à morte de um aluno dentro do estabelecimento educacional da instituição, em 2010, permitem a reflexão de que é prudente se pensar em novas formas de proteger fisicamente crianças em ambientes religiosos, no fortalecimento de projetos e programas de combate a abusos, desenvolvimento de ações para tornar as edificações onde funcionam os templos mais seguras e até aperfeiçoamento na formação dos cuidadores voluntários das crianças durante as programações. Sempre há o que se melhorar nas organizações que prezam por seus valores, missão, princípios e as crises, longe de serem apenas obstáculos, tornam-se, na verdade, aliadas que preparam o caminho para modificações importantes.

E que esta reflexão, própria da identidade organizacional, tenha sido uma contribuição importante do processo de gerenciamento da crise.

\section{Referências}

ALMEIDA, A. L. C. A construção da Reputação Organizacional. 2005. v. 2. Tese (Doutorado em Administração) - Faculdade de Ciências Econômicas, Universidade Federal de Minas Gerais, Belo Horizonte, 2005.

ALMEIDA, A. L. C. Reputação organizacional: a importância de parâmetros para o seu gerenciamento. Revista Brasileira de Comunicação Organizacional e de Relações Públicas. São Paulo, n. 2, jan/jul. 2005.

BUENO, Wilson da Costa. Comunicação empresarial: políticas e estratégias. São Paulo: Saraiva, 2009.

BUENO, Wilson da Costa. No olho do furacão: gestão e estratégias de comunicação em situações críticas. ENCONTRO DA COMPÓS, 11. Universidade Federal de Juiz de Fora, de 12 a 15 de junho de 2012.

CARRIERI, A. de P.; PAULA; A. P. P.; DAVEL, E. Identidade nas organizações: múltipla? fluida? autônoma? Organizações \& Sociedade, v. 15, n. 45, abr./jun. 2008.

CASTELLS, Manuel. O poder da identidade. Tradução Klauss Brandini Gerhardt. 2. ed. São Paulo: Paz e Terra, 1999. 530p. (A Era da Informação: economia, sociedade e cultura, 2). 
COOMBS, Timothy W. Ongoing crisis communication: planning, managing, and responding. In: JORGE, Nuno da Silva. Reputação: um elemento diferenciador e protector face a crises organizacionais. 2007. Dissertação (Mestrado). Lisboa. 2007.

COOMBS, W. Timothy; HOLLADAY, Sherry J. The Handbook of Crisis Communication. Hoboken, NJ: Wiley-Blackwell., 2010.

DILLY, Rosângela. Gerenciando a identidade organizacional sob crises e desafios contemporâneos. BOCC. Biblioteca On-line de Ciências da Comunicação, 2011.

EDUCAÇÃO ADVENTISTA. Quem somos. Disponível em: <http://www. educacaoadventista.org.br/quem-somos/>. Acesso em: 21.01.2020.

FORNI, J.J. Comunicação em tempos de crise. [Entrevista]. Organicom - Revista Brasileira de comunicação Organizacional e Relações. São Paulo: ECA/USP, 2007.

FORNI, J.J. Gestão de Crises e Comunicação: o que os Gestores e Profissionais de Comunicação Precisam Saber Para Enfrentar Crises Corporativas. São Paulo: Editora Atlas S.A, 2013.

FREITAS, M. E. Cultura organizacional: identidade, sedução e carisma? Rio de Janeiro, Editora FGV, 1999. 180p.

GÓES, Ivan. Entrevista sobre o Caso de Embu concedida, em áudio, a este autor. Abril de 2017.

IASBECK, Luiz Carlos. A Administração da Identidade: um estudo semiótico da comunicação e da cultura nas organizações. 1997. Tese (Doutorado). São Paulo, 1997.

IGREJA ADVENTISTA DO SÉTIMO DIA. Documento sobre Comunicação Adventista. 2014. p. 1. Disponível em: http://www.adventistas.org/pt/comunicacao/documento-sobre-comunicacaoadventista/>. Acesso em: 4 fev. 2018.

IGREJA ADVENTISTA DO SÉTIMO DIA. Manual de comunicação para as igrejas e grupos. 2016. Disponível em: https://downloads.adventistas.org/pt/comunicacao/livros/manual-decomunicacao-para-igrejas-e-grupos-3/. Acesso em: 02 nov. 2018.

JORGE, Nuno da Silva. Reputação: um elemento diferenciador e protector face a crises organizacionais. Dissertação (Mestrado). Lisboa, 2010. 
KENT, Michael L. What is a Public Relations “Crisis?” Refocusing Crisis Research. In: COOMBS, W. Timothy; HOLLADAY, Sherry J. The Handbook of Crisis Communication. Hoboken, NJ: Wiley-Blackwell., 2010.

KUNSCH, Margarida M.K. Planejamento de Relações Públicas na comunicação integrada. São Paulo, SP: Summus, 2003.

LUHMAN, Niklas. A improbabilidade da comunicação. Lisboa: Vega, 2006.

MACHADO, Hilka Vier. Identidade organizacional: um estudo de caso no contexto da cultura brasileira. RAE electron., São Paulo, v. 4, n. 1, June 2005 . Available from $<$ http:// www.scielo.br/scielo.php?script=sci_arttext\&pid=S1676-56482005000100012\&lng=en\&nrm=i so>. access on 21 Jan. 2020. http://dx.doi.org/10.1590/S1676-56482005000100012.

MARCONDES FILHO, Ciro. O escavador de silêncios. São Paulo: Paulus Editora, 2004.

MARCONDES FILHO, Ciro. Para entender a comunicação: Contatos antecipados com a nova teoria. São Paulo: Paulus, 2008.

SILVA NETO, B. R. da. Comunicação corporativa e reputação: construção e defesa da imagem favorável. São Paulo: Saraiva, 2010.

NEVES, Rômulo Figueira. Acomplamento estrutural, fechamento operacional e processos sobrecomunicactivos na teoria dos sistemas sociais de Niklas Luhman. 2005. Dissertação (Mestrado em Sociologia) - Universidade de São Paulo, São Paulo.

PRESTES, J. E. Comunicação de risco, elemento chave na gestão de crises corporativas e um desafio para o século XXI: a teoria na prática, situação atual e tendências. In: ORGANICOM 2007. São Paulo: Gestcorp - ECA-USP, 2007.

RBS TV. Dez anos depois, morte de menina em pia batismal de Joinville ainda não foi esclarecida. Disponível em: https://g1.globo.com/sc/santa-catarina/noticia/dez-anos-depoismorte-de-menina-em-pia-batismal-de-joinville-ainda-nao-foi-esclarecida.ghtml). Acesso em: 14 jun 2019.

TORQUATO, Gaudêncio. Tratado de comunicação organizacional e política. São Paulo: Thomson, 2002. 
ULMER, Robert; SELLNOW, Timoty L.; Matthew W. SEEGER. Considering the future of crisis communication research: understanding the opportunities inherent to crisis events through the discourse of renewal. In: COOMBS, Timoty; HOLLADAY, Sherry J. The handbook of crisis communication. United Kingdom, Blackwell Publishing, 2010.

1 Jornalista pela Universidade do Sul de Santa Catarina (UNISUL) e especialista em Comunicação Corporativa (UNISUL) e Marketing Estratégico (Centro Universitário Adventista de São Paulo UNASP). Mestre em Comunicação - Universidade Católica de Brasília (PPGCOM/UCB), linha Processos Comunicacionais nas Organizações. Assessor de Comunicação da Divisão Sul-Americana da Igreja Adventista do Sétimo Dia (DAS - Brasil).E-mail: felipex29@gmail.com

2 Coordenadora do PPGCOM/UCB. Possui graduação em Letras - Universidade Paul Valéry Montpellier, França (1995), Mestrado em Didactologia das Línguas e Culturas - Universidade de Paris III - Sorbonne-Nouvelle (1997) e Doutorado em Didactologia das Línguas e Culturas - Universidade de Paris III - Sorbonne-Nouvelle (2002). Fez pós-doutorado no Programa de Pós-graduação em Comunicação, Faculdade de Comunicação da Universidade de Brasília, UnB. Tem experiência na área de Comunicação, com ênfase em Comunicação e Cultura, atuando principalmente nos seguintes temas: comunicação, poesia, diálogo, comunicação intercultural e literatura. E-mail: florence@ucb.br

3 Jornalista, mestre e doutor em Comunicação e Semiótica. Professor e pesquisador do mestrado em Comunicação da Universidade Católica de Brasília (PPGCOM/UCB), linha Processos Comunicacionais nas Organizações. E-mail: iasbeckk@gmail.com

4 Jornalista, mestre e doutor em Comunicação. Professor e pesquisador do mestrado em Comunicação da Universidade Católica de Brasília (PPGCOM/UCB), linha Processos Comunicacionais nas Organizações. Líder do grupo Prêmios, Indicadores e Estratégias em Comunicação. E-mail: robson.dias@ucb.br 